Revista Mídia e Cotidiano Artigo Seção Livre ISSN 2178-602X

Volume 15, Número 3, set-dez/2021

Submetido em: 23/11/2020

Aprovado em: 27/07/2021

\title{
Resistência constitucional, sociedade civil interveniente e princípio poliárquico: horizontes de sobrevivência para a Empresa Brasil de Comunicação
}

\section{Constitutional resistance, intervening civil society and polyarchic principle: survival horizons for Empresa Brasil de Comunicação}

Resistencia constitucional, sociedad civil interviniente y principio poliarquico:
horizontes de supervivencia para la Empresa Brasil de Comunicaciónportuguês

\author{
Álvaro Nunes LARANGEIRA ${ }^{1}$ \\ Jeaniel Carlos MAGNO²
}

\section{Resumo}

O governo Bolsonaro tem reiterado o propósito de privatizar ou extinguir a Empresa Brasil de Comunicação (EBC). O presente ensaio, permeado por indicadores conceituais e experiências internacionais exitosas em sistemas públicos de comunicação, aponta para a sobrevivência da empresa a recorrência aos princípios constitucionais da Carta Magna de 1988, a interveniência da sociedade civil e a aplicação das premissas poliárquicas, tendo em vista ser a empresa estatal paradigmática na inconstante e complicada implementação de políticas de comunicação pública no igualmente instável campo nacional da economia política da informação, da comunicação e da cultura.

Palavras-chave: Empresa Brasil de Comunicação. Radiodifusão. Política de comunicação. Sistema público de comunicação.

\footnotetext{
Abstract

The Bolsonaro government has reiterated the purpose of privatizing or extinguishing Empresa Brasil de Comunicação (EBC). The present essay, permeated by conceptual indicators and successful international experiences in public communication systems, points to the survival of the company the recurrence to the constitutional principles of the

${ }^{1}$ Doutor em Comunicação pela Pontifícia Universidade Católica do Rio Grande do Sul, com pósdoutoramento em Jornalismo na Universidade de Coimbra, Portugal, com bolsa do CNPq. Coorganizador da Rede de Pesquisa Jornalismo, Imaginário e Memória - Rede JIM. E-mail: alvarolarangeira@ hotmail.com. Orcid: 0000-0002-7849-398X.

${ }^{2}$ Mestre em Comunicação e Linguagens pela Universidade Tuiuti do Paraná. Bacharel em Comunicação Social com habilitação em Relações Públicas pela Universidade Federal do Paraná. E-mail: jeaniel.magno@gmail.com. Orcid:0000-0002-0650-1071.
} 
1988 Constitution, the intervention of the civil society and the application of polyarchic premises, in order to be the paradigmatic state company in the fickle and complicated implementation of public communication policies in the equally unstable national field of the political economy of information, communication and culture.

Keywords: Empresa Brasil de Comunicação. Broadcasting. Communication policy. Public communication system.

\section{Resumen}

El gobierno de Bolsonaro ha reiterado el propósito de privatizar o extinguir la Empresa Brasil de Comunicacão (EBC). El presente ensayo, impregnado de indicadores conceptuales y experiencias internacionales exitosas en sistemas de comunicación pública, apunta a la supervivencia de la empresa, la recurrencia a los principios constitucionales de la Constitución de 1988, la intervención de la sociedad civil y la aplicación de premisas poliarquicas, para ser la empresa estatal paradigmática en la implementación cambiante y complicada de las políticas de comunicación pública en el campo nacional igualmente inestable de la economía política de la información, la comunicación y la cultura.

Palabras clave: Empresa Brasil de Comunicação. Radiodifusión. Política de comunicación. Sistema de comunicación pública.

\section{Introdução}

Embora a contribuição da infraestrutura do sistema de comunicação no Brasil tenha sido significativa para o desenvolvimento do país e os princípios que regem as políticas públicas de comunicação, abrangência e significado, estejam cercados de relevância, esses são temas que tradicionalmente passam à margem das discussões e do interesse da sociedade, ainda que essenciais para a construção de um cenário democrático consolidado e em relação direta com o cotidiano da sociedade. Entes midiáticos são atores protagonistas nas práticas sociais da vida cotidiana contemporânea. Dizem respeito a produções de sentido representativas das dinâmicas coletivas e individuais da sociedade reportada e representações dos modos de vida e interpretações e intervenções políticoideológicas das forças políticas em interação com os públicos e audiências.

Por esse motivo, com o pretexto de dar ênfase a um tema que geralmente está distante da agenda social, o presente artigo trata dos subsídios que assegurariam a manutenção da Empresa Brasil de Comunicação (EBC), com a finalidade de projetar um panorama apoiado em indicadores conceituais que apontem perspectivas futuras, a 
despeito da reiterada ameaça do governo Bolsonaro em privatizar ou extinguir a empresa pública de comunicação. Especificamente visa a caracterizar as experiências provocadas por outros sistemas públicos de comunicação no mundo; compará-las a uma radiografia histórica da EBC; e por meio de um monitoramento registrar o deslocamento de aportes que o atual governo transfere a essa instituição.

Com base nos princípios estabelecidos na Constituição Federal de 1988, no capítulo V do título VIII da Carta Magna, relativos à regulamentação das emissoras de radiodifusão e da imprensa brasileira, e nos conceitos alusivos às políticas públicas de comunicação, o traçado metodológico consiste em monitorar e analisar como o atual governo tem minado os aportes que sustentam a empresa e se o fortalecimento democrático da $\mathrm{EBC}$ - de interesse, utilidade e alcance à população - pode se configurar no mecanismo de subsistência da instituição. Portanto, trazer à tona o alcance e a relevância de políticas públicas duradouras para o setor de comunicação social. Os elementos que compõem a natureza institucional dessas ações para o Estado e a sociedade demarcam o ponto de partida e o eixo central da abordagem da pesquisa a seguir.

\section{Do preconceito à concepção do ideal}

Desde a composição do Código Brasileiro de Telecomunicações, sancionado em 27 de agosto de 1962 pela Lei 4.117, uma série de outros eventos posteriores ensaiou a possibilidade de um projeto consistente, relativo às políticas públicas para o setor de comunicação social. Enfim seria posto em prática para sanar uma demanda que já se arrastava desde a era Vargas, pelo menos. Mas foi com o advento da Assembleia Nacional Constituinte, que destinou um capítulo específico à Comunicação Social na Constituição Federal promulgada em 1988, nos artigos 220 a 224, que a ação precursora se materializou e abriu perspectivas para um cenário apropriado à regulamentação de um setor estrutural para a consolidação da democracia (PIERANTI, 2006).

Assim, coube à Constituição Federal de 1988, no artigo 220, preservar explicitamente a liberdade de expressão; no artigo 221, determinar os princípios que devem orientar a programação das emissoras de rádio e de televisão; no artigo 222, estabelecer as diretrizes relativas à propriedade das empresas de radiodifusão e de imprensa; no artigo 223, compor as diretrizes para a regulamentação das outorgas e 
concessões de emissoras de radiodifusão; e no artigo 224, prescrever a institucionalização de um organismo fiscalizador da comunicação social (BRASIL, 1994; PIERANTI, 2006).

Com isso, para mensurar a extensão e a importância de um sistema público de comunicação, com políticas públicas sustentáveis para o setor de comunicação e com ações de caráter institucional, que fortaleçam a relação Estado-sociedade, é preciso, de antemão, identificar no tempo presente os agentes envolvidos e dispostos a estruturar tal sistema e a elaborar tais políticas.

Filiados a isso, tradicionalmente no âmbito democrático Estado e meios de comunicação apresentam uma ligação contrastante, pois ao Estado é reservado o papel de regulador dos meios de comunicação, ao mesmo tempo em que é o depositário da liberdade de imprensa, seja ela impressa, televisiva, radiofônica ou outro meio, e caso seja constatado abuso nas publicações noticiadas, futuras sanções estão previstas na legislação atual (PIERANTI, 2006).

Nesse aspecto, os holofotes se voltam para dois fundamentos vinculados à natureza da democracia, que estão amparados de maneira subentendida na Carta Magna de 1988 e tratados categoricamente por Robert Dahl (2012): a veracidade comprovada da liberdade de expressão; e de fontes de informação diversificadas, como qualidades de um Estado moderno (PIERANTI, 2006). No tocante à Constituição Federal de 1988, no capítulo V do título VIII da Carta Magna, o artigo 220 prescreve que:

A manifestação do pensamento, a criação, a expressão e a informação, sob qualquer forma, processo ou veículo, não sofrerão qualquer restrição, observado o disposto nesta Constituição. $\S 1^{\circ}$ Nenhuma lei conterá dispositivo que possa constituir embaraço à plena liberdade de informação jornalística em qualquer veículo de comunicação social, observado o disposto no art. $5^{\circ}, \mathrm{IV}, \mathrm{V}, \mathrm{X}, \mathrm{XIII}$ e XIV; $\S 2^{\circ}$ É vedada toda e qualquer censura de natureza política, ideológica e artística (BRASIL, 1994, p. 99).

Quanto à funcionalidade dos meios de comunicação, Pieranti (2006) aponta para o conceito de poliarquia difundido por Robert Dahl (2012, p. 346), que envolve concepções como:

1. Fruto do empenho pela democratização das instituições do Estado;

2. Categoria particular de diretriz ou procedimento político; 
3. Meio de subsistência para lograr vantagens em períodos eleitorais;

4. Um composto de proteção aos direitos políticos; ou

5. Um complexo de instituições essenciais à performance do processo democrático em proporções ampliadas.

Além disso, Dahl (2012) considera como garantias essenciais para que um governo se estabeleça na condição e na qualidade de poliarquia reconhecer: funcionários eleitos; eleições livres e justas; sufrágio inclusivo; direito a concorrer a cargos eletivos, autonomia associativa e, notoriamente, a liberdade de expressão e o acesso à informação alternativa, posto que:

Os cidadãos têm o direito de se expressar, sem o perigo de punições severas, quanto aos assuntos políticos de uma forma geral, o que inclui a liberdade de criticar os funcionários do governo, o governo em si, o regime, a ordem socioeconômica e a ideologia dominante. [...]. Os cidadãos têm o direito de buscar soluções alternativas de informação. Ademais, existem fontes de informação alternativa protegidas por lei (DAHL, 2012, p. 351).

Embora uma das perspectivas anteriores vincule o conceito de poliarquia a um mecanismo de controle para lograr vantagens em períodos eleitorais diante dos demais panoramas retratados e diagnosticados como singulares para um projeto maior de democracia, pode-se dizer que, não raras vezes, esses movimentos contrários são de natureza preconcebida e em boa medida tendenciosa, pois classificam o meio de comunicação em foco como de propriedade do governo da vez. Portanto, é "chapabranca", e por mais que outros fundamentos subsidiem a manutenção de uma TV pública, ainda assim serão inconsistentes aos olhos dos facciosos (LEAL FILHO, 2009).

Com efeito, neste caso, o mais produtivo é construir "pontes" para que o conceito de poliarquia se configure num complexo de instituições essenciais à performance do processo democrático em proporções ampliadas, assim definido por Dahl (2012). Porque os laços sociais que conectam as instituições que compõem o Estado têm legitimidade e força para assegurar investimentos de caráter democrático em políticas públicas para a comunicação. Na prática, pode-se inferir que este ambiente é a base do processo e os laços ali constituídos refletem uma sociedade entre cidadãos, capaz de patrocinar tal 
investimento e de produzir tal engajamento. Isto é, desenvolve-se aí uma sociedade de um com os outros, comumente chamada de sociedade civil.

Ora, se para Gramsci o Estado é composto por instituições, como as igrejas, escolas, sindicatos e outras, que juntas formam uma sociedade civil (COUTINHO, 1992) e se para Marx é a sociedade civil que mantém e coordena o Estado (BOBBIO, 1982), logo, se as instituições que integram a chamada sociedade civil concorrerem no sentido de assegurar políticas públicas duradouras, teoricamente, a consolidação da democracia estará ao alcance das mãos em virtude desses laços institucionais.

Em tal caso, é vital salientar que o investimento no direito à comunicação, à informação de interesse e utilidade pública, à liberdade de expressão, à fonte de informação diversificada e à participação efetiva e indistinta do cidadão nas discussões e nas decisões relativas aos temas de interesse público compreende a matriz almejada por aqueles que acreditam que o setor estrutural da comunicação social pode ser um aliado de peso no esforço conjunto em prol da consolidação da democracia. Situação que requer o engajamento da sociedade civil na causa.

Nesse aspecto, uma vez que a política é o cerne da democracia e em razão da influência que emana da relação entre a comunicação e a política, buscar alternativas sustentáveis em termos de políticas públicas de comunicação requer uma releitura e um resgate histórico do sentido de sociedade civil para os dias atuais (RAMOS, 2007), porque a concepção proposta por Gramsci foi subtraída do processo democrático brasileiro, e no seu lugar foi articulado um raciocínio neoliberal, no qual a despolitização, a desideologização e a inclinação a uma postura acrítica ocupam o imaginário do senso comum brasileiro (RAMOS, 2007, p. 47).

Além disso, a noção de sociedade civil no Brasil também está associada à imagem de um esforço combinado para reduzir a concentração de poder dos meios de comunicação e igualmente ligada aos movimentos sociais, principalmente aqueles vinculados às correntes de esquerda, que até hoje se identificam como sociedade civil, em oposição à ditadura militar que deixou marcas negativas no imaginário de boa parcela dos brasileiros (RAMOS, 2007). Por isso, dada a ideia que uma camada relativa da sociedade brasileira faz do conceito de sociedade civil, pode-se deduzir que uma parcela 
similar da sociedade está inserida naquilo que Chomsky (2014, p. 14) chamou de “democracia de espectadores". Logo, vale registrar com cautela que:

[...] onde a sociedade civil é fraca, onde as tradições de democracia política e de organização popular autônoma são débeis ou inexistentes, a passagem para uma nova ordem não pode contar com os mesmos pressupostos que numa sociedade "ocidental"; e, desse modo, torna-se necessário um período "ditatorial", de fortalecimento do Estadocoerção (COUTINHO, 1992. p. 84).

Adiante, na trilha das teorias clássicas sobre o conceito de sociedade civil, teóricos como Jürgen Habermas, Andrew Arato \& Jean Louise Cohen e Anthony Giddens deixaram também suas contribuições acerca do assunto. Particularmente em Habermas, a interpretação vigente "da expressão 'sociedade civil' não coincide com a da 'sociedade burguesa', da tradição liberal, que Hegel chegara a tematizar como 'sistema das necessidades', isto é, como sistema do trabalho social e do comércio de mercadorias numa economia de mercado" (1997, p. 99). Seu eixo institucional é constituído basicamente por associações e organizações livres, não estatais e não econômicas, inclusas aí as estruturas de comunicação de natureza pública que integram os interesses sociais cotidianos, tais como os movimentos, organizações, associações, que "captam os ecos dos problemas sociais que ressoam nas esferas privadas, condensam-nos e os transmitem, a seguir, para a esfera pública política" (HABERMAS, 1997, p. 99).

O desenvolvimento teórico proposto por Habermas sobre sociedade civil teve importante contribuição também para pesquisadores como Andrew Arato \& Jean Louise Cohen, que perceberam ali não uma construção teórica conceitual acerca do tema, mas os recursos necessários para defenderem sua própria versão sobre sociedade civil (ARATO \& COHEN, 1994).

Como menção ao investimento teórico proposto por Arato \& Cohen (1994), vale destacar que para os autores a concepção ideal de sociedade civil requer uma distinção concreta entre Estado, sociedade civil e economia, para que o fator independência efetivamente se realize. Tem como núcleo institucional associações de caráter voluntário e, portanto, sem vínculo com o Estado e com os meios econômicos, deixando assim de 
fora instituições como partidos políticos e sindicatos, mas também as instituições religiosas, as universidades e outros tantos organismos filiados a essa lógica.

Já para Anthony Giddens (1999), a proposta que o estudioso desenvolve sobre o conceito de sociedade civil passa substancialmente pela construção teórico-metodológica de uma terceira via, na qual "o governo pode agir em parceria com instituições da sociedade civil para fomentar a renovação e o desenvolvimento da comunidade [...] a nova economia mista. Essa economia só pode ser eficaz se as instituições de welfare existentes forem inteiramente modernizadas" (GIDDENS, 1999, p. 79). Um dos grandes imbróglios é que na visão neoliberal o Estado precisa ser encolhido e na concepção histórica social-democrata o plano se dá na direção contrária. Diante de mais esse impasse, a receita, para Giddens, é reconstruí-lo (GIDDENS, 1999, p. 81).

Assim sendo, é inadiável que ações mobilizadoras resgatem o significado e o papel representativo que compete à sociedade civil. Isto é, o de tomar frente nas questões relativas às políticas públicas para a comunicação. Posto que tanto na visão clássica de Marx quanto na percepção de Gramsci, a sociedade civil reflete o deslocamento atuante e decisivo da edificação histórica (BOBBIO, 1982). E somado a esse entendimento, para Gramsci:

Com a intensificação dos processos de socialização da política, com algo que ele chama algumas vezes de estandardização dos comportamentos humanos gerados pela pressão do desenvolvimento capitalista, surge uma esfera social nova, dotada de leis e de funções relativamente autônomas e específicas, e - o que nem sempre é observado - de uma dimensão material própria. É essa esfera que ele vai chamar de sociedade civil (COUTINHO, 2011, p. 14).

Assim, sob a égide da Constituição Federal de 1988, artigos 220 a 224, e num contexto em que a sociedade civil pressiona o Estado,

Espera-se que ao se utilizar os termos Serviço Público ou Interesse Público para as Comunicações, não haja sinonímia possível. Se a escolha terminológica é por Interesse Público, fica claro que são as condições, omissas ou expressas, para a cessão do espectro à exploração de negócio privado. Ao se usar o termo Serviço Público, claramente se refere à obrigatoriedade do Estado em garantir um direito ao cidadão 
que representa, seja direta ou indiretamente (SANTOS; SILVEIRA, 2007, p. 78-79).

O propósito é fortalecer a democratização das instituições do Estado, orientar os procedimentos políticos e assegurar a proteção aos direitos políticos, ainda que uma parcela restrita da população desqualifique iniciativas em projetos vinculados ao sistema público de comunicação e políticas públicas para um setor estrutural como o da comunicação, por acreditar que se trate de um meio para que o governo obtenha vantagens em períodos eleitorais. A perspectiva central apresentada por Dahl (2012) prevê a constituição de um complexo de instituições essenciais à performance do processo democrático em proporções ampliadas, e isso é expressivo.

Enfim, os aspectos aqui levantados e interpretados não esgotam as demandas teóricas que envolvem a cobertura proposta, mas se apoiam nas alegações de Thomas Kuhn (1998), ao procurar acrescentar alguns pressupostos às discussões de um campo de estudo, em que as referências que orientam suas práticas ainda não estão consolidadas. Assim sendo, além das características já levantadas, a valorização do sistema público de comunicação e o investimento em políticas públicas que fomentem a inserção daqueles que não têm voz se oferecem como indicadores conceituais a fim de parametrizar as experiências provocadas por outros sistemas públicos de comunicação no mundo - a seguir historiados - e compará-las ao modelo brasileiro.

\section{Experiências em políticas públicas de comunicação no mundo e no Brasil}

Inicialmente, para Valente (2009a), o termo "sistema público de comunicação" é o predominante no Brasil, embora em outros países, apesar de prevalecer a mesma ideia de "sistema", a expressão usual seja "public service broadcasting", para enfatizar que os meios de comunicação têm um caráter público ou para designar uma rede de emissoras de TV e rádio. Para sintetizar os diferentes sentidos, o autor adota o termo "mídia pública", a qual retrata em seis modalidades distintas (VALENTE, 2009a, p. 26-42):

1. Elitista - de origem britânica e viés iluminista: prioriza o conhecimento e a razão; é uma ferramenta de alto alcance e veicula o melhor da ciência, alta cultura, informação jornalística e conteúdo educativo; o impasse é que isto contempla os interesses e o perfil de audiência da alta sociedade, enquanto que o restante do 
coletivo é impelido a acatar um olhar elitista de mundo, explica Granham (1990 apud Valente, 2009a, p. 27);

2. Educativa - difundida na América Latina: prioriza a propagação de conteúdo educativo; mas o impasse está em fixar a atenção somente sobre as carências reais, sem abordar as necessidades reais do processo educacional, revela Burke (1971 apud Valente, 2009a, p. 32);

3. Pública não estatal - visa a assegurar a produção autônoma de conteúdo destinada ao público, dado que é imperativo se resguardar da influência do mercado e da gestão do governo, a fim de garantir que um enfoque abrangente de reflexão se estabeleça; e garantir a liberdade editorial na produção de conteúdo imparcial e crítico, que favoreça autonomia ao cidadão para se posicionar diante de questões colocadas em discussão ou em votação;

4. Pública como alternativa à mídia comercial - cabe aos veículos comerciais a incumbência de fornecer conteúdo educativo, artístico, cultural e informativo ao cidadão; cabe à TV pública atuar na pluralidade de públicos, com o objetivo de debater com estes, suas exigências informativas e culturais;

5. Culturalista - ligada à corrente dos Estudos Culturais: defende para todo o continente latino-americano que a mídia pública tenha como traços capitais a autonomia e um engajamento social que valorize a diversidade cultural e a cultura nacional, frente a um processo globalizante que encerra numa desterritorialização a ideia de nação, ao mesmo tempo em que desloca o sentido da palavra "público" e desarticula a ideia de uma produção cultural própria, fomentada pelos avanços tecnológicos que potencializam a propagação dos meios de produção cultural em nível global; e

6. Aparelho de Estado - tradição marxista: parte-se do pressuposto que o Estado é o tutor das garantias de domínio de uma classe sobre a outra, pois o propósito é inibir qualquer oposição ao sistema e assim o domínio se estabelece pela força e por meio de uma orientação cultural, estruturada por aparelhos de hegemonia, formados por instituições públicas, mantidas pelo Estado, como as escolas, os partidos políticos, as igrejas e os meios de comunicação. 
As seis modalidades acima inferem aspectos ligados à proposição de sociedade civil e projetos voltados às políticas públicas de comunicação. O retrato de um sistema público não estatal se destaca como referência para caracterizar as experiências provocadas por outros sistemas públicos de comunicação no mundo e para compará-las a uma radiografia histórica da $\mathrm{EBC}$.

Ao adentrar nas peculiaridades dos sistemas públicos de comunicação em vigor ao redor do mundo, por critérios de seleção os fatores associados à diversidade, tradição democrática e pioneirismo em sistemas públicos de comunicação foram os traços examinados para se chegar à realidade praticada em três países europeus, a fím de comparar essas práticas com as da EBC.

De antemão, vale registrar que as três referências apuradas, desde o final da $2^{\mathrm{a}}$ guerra, partilham o fato de que tradicionalmente os recursos aplicados para a manutenção do serviço público de radiodifusão provêm regularmente e em larga escala de taxas pagas pelos cidadãos, diferentemente da versão brasileira que organizou suas bases majoritariamente assentadas num modelo subsidiado pela propaganda (LEAL FILHO, 2009). Contudo, há outros fatores singulares ocorridos no contexto pós-guerra que, delineados a seguir, merecem destaque.

De acordo com Valente (2009b), os recursos que sustentam a manutenção do serviço público de radiodifusão na Alemanha provêm em larga escala das taxas de licença de sinal cobradas dos usuários e pelas receitas da veiculação de anúncios publicitários obtidas com restrição. Dados revelam que em 2007 as TVs geraram 42,5\% do share de audiência e as rádios 27,8\%. A estrutura é dirigida por um conselho administrativo e outro de radiodifusão, orientados por uma base (política, religiosa, sindical, empresarial, de defesa e de direito). Somados a esses indicadores, a tabela a seguir (tabela 1) fornece outros subsídios para análise:

Tabela 1 - Serviço público de radiodifusão na República da Alemanha

(continua)

\begin{tabular}{|c|c|c|c|c|c|}
\hline Emissoras & Cobertura & Conteúdo/tema & Caráter & Objetivos & Princípios/missão \\
\hline $\mathrm{ZDF}$ & Nacional & Informativo/cultura & Generalista & interesse públicı & Distribuição \\
\hline ARD & Estadual & Educativo/científicc & Finalidade & Inserção a cidadania & Descentralização \\
\hline
\end{tabular}


Tabela 1 - Serviço público de radiodifusão na República da Alemanha

(continuação)

ARD Regional Histórico/variedade Investir em Independência editoria Modelo federativo

Canal ARD Nacional Ativ. Parlamentares (Audiência) Abertura e clareza Investimento em

\begin{tabular}{lll}
\hline Rádios Nacional Entretenimento/Artı $\quad$ Valorizar a diversidade (Temas regionais)
\end{tabular}

Fonte: Adaptado de Valente (2009b)

Segundo Valente (2009c), os aportes que asseguram o serviço público de radiodifusão na França provêm da taxa de licença cobrada junto com o tributo habitacional dos moradores; e das receitas provenientes de patrocínios, serviços e publicidade com restrição. Dados revelam que em 2007 as TVs geraram 41,8\% do share de audiência e as rádios alcançaram 28\%. A estrutura é formada pelo governo, Parlamento e o Conselho Superior do Audiovisual, que monitora a programação e participa da indicação dos diretores das emissoras.

Tabela 2 - Serviço público de radiodifusão na França

\begin{tabular}{cccccc}
\hline Emissoras & Cobertura & Conteúdo/tema & Caráter & Objetivos & Princípios/missão \\
\hline France & Nacional & Informativo/cultura & Generalista & Debate democrático & Identidade nacional \\
Telévisions & Conteúdo & Educativo/científicc Finalidade & Inserção a cidadania & Prezar a língua mãe \\
$2,3,4,5$ & P/região & Histórico/econômic & Investir em & Inclusão social & Clareza nos Atos \\
RFO & Colônias & Interativo/criativo & (Audiência) & Diversidade/criatividac & Vedada veiculação \\
\hline Rádios & Nacional & Entretenimento/Art & Pesquisas de opinião & (Político/ideológica), \\
\hline
\end{tabular}

Fonte: Adaptado de Valente (2009c).

Conforme Valente (2009d), os subsídios que sustentam o serviço público de radiodifusão no Reino Unido decorrem da taxa de licença anual cobrada dos contribuintes possuidores de TV e de rádio; resultam das vendas de livros, DVDs, produtos e programas da $\mathrm{BBC}$ vendidos para outros países em função da proibição de receitas advindas de anúncios publicitários. Dados revelam que em 2007 as TVs alcançaram 33,8\% do share de audiência e as rádios 54,9\%. A estrutura segue as diretrizes fixadas na Carta Real e posta em prática pelos conselhos formados por representantes dos interesses dos contribuintes da taxa; por representantes dos países que constituem o Reino Unido; por 
conselhos de audiência que expõem as críticas dos contribuintes; por um comitê de ordem editorial; um comitê de ordem religiosa; e mediante pesquisas de opinião que avaliam em tempo real a qualidade do serviço. Detalhes na tabela abaixo (tabela 3):

Tabela 3 - Serviço público de radiodifusão no Reino Unido

\begin{tabular}{llllcc}
\hline Emissoras & Cobertura & Conteúdo/tema & Caráter & Objetivos & Princípios/missão \\
\hline BBC-1 a 4 & Nacional & Informativo/cultura & Generalista & Temas interesse públicı & Serv. alta qualidade \\
Precursora & Conteúdo & Educativo/noticioso Finalidade & Inserção a cidadania & Inovador/atrativo/ \\
(Conceito) & P/região & Interativo/criativo & Investir em & Autonomia editorial & Original e desafiado \\
Serv. Pub. & TV-rádio & Ativ. Parlamentares & (Audiência) & Abertura e transparênc & Mix. Programação \\
\hline (Comunic.) & Internet & Divertimento factua & & Pesquisas de opinião & (Infantil ao adulto)
\end{tabular}

Fonte: Adaptado de Valente (2009d).

Ora, a simetria que há entre as três tabelas acima revela traços como: [1] a taxa de licença subsidia o serviço público de radiodifusão; [2] o conselho é constituído por representantes da sociedade civil; [3] a cobertura é nacional, com conteúdo regional, foco na diversidade e interesse público, com independência e transparência; [4] há o estímulo ao debate democrático através da inserção social e a cidadania; [5] o conteúdo é informativo, cultural, educativo, de lazer e de caráter generalista, para ampliar a audiência; e [6] as pesquisas de opinião sondam e captam as sugestões e críticas do cidadão.

Portanto, os seis traços aqui destacados tornam-se parâmetros para o modelo de sistema público de comunicação no Brasil, e conforme Valente (2009e), a primeira tentativa de estabelecer um padrão de radiodifusão foi no início da década de 1930, com a antiga Rádio Sociedade do Rio de Janeiro renomeada Rádio MEC (Ministério da Educação e Cultura) e transferida em doação por Edgard Roquette-Pinto ao governo federal, com a ideia de preservar o caráter educativo.

A segunda tentativa foi a Rádio Nacional do Rio de Janeiro, criada na década de 1930 na gestão e manejo do governo Vargas. Com o crescimento industrial e a falta de trabalhadores qualificados para suprir as demandas da indústria, em 1967 o governo 
militar criou as TVs Educativas. Na década de 1970, o governo passou a gerir diretamente as emissoras, período em que foi ao ar a TVE do Rio de Janeiro, e a Empresa Brasileira de Radiodifusão (Radiobrás) é criada para explorar os serviços de rádio e TV do governo. Mas foi entre 2006 e 2007 que surgiu a ideia e a criação da Empresa Brasil de Comunicação, que logo foi aprovada e transformada em lei em 2008.

A Empresa Brasil de Comunicação resultou das discussões do I Fórum Nacional de TVs Públicas, realizado em Brasília em 2007, e iniciou as atividades em outubro do mesmo ano com a Medida Provisória 398/2007, transformada em abril do ano seguinte na Lei 11.652, a qual estabelecia ser a EBC vinculada à Secretaria de Comunicação Social (SECOM) da Presidência da República e determinada ao cumprimento dos princípios e objetivos arrolados naquela lei, dentre os quais

VIII - autonomia em relação ao Governo Federal para definir produção, programação e distribuição de conteúdo no sistema público de radiodifusão; e IX - participação da sociedade civil no controle da aplicação dos princípios do sistema público de radiodifusão, respeitando-se a pluralidade da sociedade brasileira (BRASIL, Lei ${ }^{\circ}$ $11.652,2008)$.

Murilo César Ramos, coordenador do Laboratório de Políticas de Comunicação da Universidade de Brasília (LaPCom/UnB) e integrante do Conselho Curador da EBC entre 2010-2015, apontaria quatro problemas de origem na formulação da empresa de comunicação idealizada como um sistema de serviço público de radiodifusão. O primeiro aspecto foi vincular a EBC à SECOM, ligada à Presidência da República, fato gerador das críticas de relacionar a empresa ao discurso governamental. $\mathrm{O}$ segundo aspecto, decorrente do primeiro, a implementação de um jornalismo desprovido de criticidade; em terceiro lugar, alocar a sede da EBC nas instalações da NBR, canal efetivo de divulgação do governo federal; e por último, a judicialização por empresas de comunicação e operadoras de telecomunicações do pagamento da Contribuição para o Fomento da Radiodifusão Pública (CFRP), reforçando a dependência financeira da instituição com o Poder Executivo (RAMOS, 2019).

Pesquisador também de ponta em radiofusão, recorrente a Dahl em seus trabalhos e chefe de gabinete da EBC no biênio 2010-2011, Octavio Penna Pieranti concordaria com parte da crítica do colega. A EBC fora formada para gerenciar as emissoras de 
radiodifusão pública e, por lei, coordenar a comunicação governamental. Porém, havia exemplos de administração exitosa em situações correlatas de junção das comunicações pública e estatal e, ressaltaria o especialista, seria equivocado desconsiderar a estrutura existente da Radiobrás e das emissoras de rádio Nacional FM, Nacional de Brasília, Nacional do Rio de Janeiro, Nacional da Amazônia, Nacional do Alto Solimões, MEC FM e Rádio MEC. "Isso envolveria, dentre outros aspectos, inúmeros concursos públicos para contratação de mão de obra, duplicação de investimentos e disputa por espaço no espectro, com grandes chances de insucesso" (PIERANTI, 2018, p. 142).

Considerada herdeira da antiga estrutura de serviço público de radiodifusão, a EBC foi engendrada para propiciar a primeira experiência em TV genuinamente pública (VALENTE, 2009e, p. 270-274), retratada em detalhes na tabela a seguir (tabela 4):

Tabela 4 - Serviço público de radiodifusão no Brasil (EBC)

\begin{tabular}{lllll}
\hline Emissoras & Cobertura & Conteúdo/tema & Caráter & \multicolumn{1}{c}{ Objetivos em aberto } \\
\hline EBC-Portal & Internet & Informativo/cultura & Generalista & Verticalização dificulta a diversidad \\
EBC-Rádio & Nacional & Educativo/noticioso Em conteúdo & A produção restrita da TV Brasil \\
1-TV Brasil & Nacional & Artístico/regional & Jornalístico & Compromete a grade das afiliadas \\
2-TV NBR & Nacional & Ativ.Poder Executi & (Programa) & Maior parte da programação vem da \\
\hline 3-TV Integratior & Internac. & Fatos do continente & Infantil/cultura & (TV Cultura SP e acervos da TVE) \\
\hline
\end{tabular}

Fonte: Adaptado de Valente (2009e).

Segundo Valente (2009e, p. 281), os recursos que garantem o serviço público de radiodifusão da EBC decorrem das "dotações orçamentárias, prestação de serviços, doações, distribuição da publicidade legal do poder executivo, apoios culturais, publicidade institucional" e leis de incentivo à cultura. Já a estrutura da EBC é (era) composta por um conselho curador administrativo, executivo e de fiscalização, formado por membros do governo, representantes da sociedade civil, indicações da Secretaria Especial de Comunicação Social e outros.

Sendo assim, a partir da radiografia histórica apresentada e apoiado nos parâmetros recolhidos das experiências do serviço público de radiodifusão na Alemanha, 
França e Reino Unido, nota-se que a fórmula difusa e submissa pela qual se obtém os recursos para garantir a manutenção do serviço público da EBC compromete a autonomia editorial, a transparência e o interesse público em jogo. A lógica praticada para conduzir a estrutura restringe a função da sociedade civil, a fiscalização e a participação nas tomadas de decisões.

A precariedade técnica de produção e de conceitos dificulta a cobertura no território nacional e limita o incentivo à diversidade, à valorização das raízes culturais e regionais e à informação alternativa; a ausência de iniciativa que estimule o debate democrático compromete a inserção social e a cidadania. O caráter generalista de conteúdo adotado, distinto dos moldes internacionais, embaraça a métrica da audiência, e a escassez de canais interativos disponíveis para captar sugestões e críticas inibe a participação do cidadão.

Isso remete ao entendimento que os representantes da sociedade civil dos países citados são atuantes e isso favoreceu a criação do sistema público de comunicação aos moldes que lá vigoram. Logo, a efetiva existência da TV pública no Brasil depende do empenho e postura da sociedade civil brasileira (espectadores ou protagonistas atuantes). É preciso sondar o enfraquecimento da edificação da EBC iniciado em 2016 no governo Temer - com a destituição do presidente da EBC, alteração do estatuto social e a supressão do termo "pública" da expressão "comunicação pública" no Mapa Estratégico da empresa, documento institucional das ações e planejamentos futuros (LARANGEIRA, 2018, p. 6) - e analisar o fortalecimento democrático de interesse, utilidade e alcance para a população como mecanismo de resistência e sobrevivência da empresa ameaçada de privatização pela nova direção, o governo Bolsonaro.

\section{Sob a nova direção}

Ainda na fase de campanha, o então candidato à presidência da República Jair Messias Bolsonaro afirmou que iria extinguir ou privatizar a EBC com o objetivo de 
reduzir os gastos do erário público ${ }^{3}$. É nesse contexto de tragédia anunciada que em $1^{\circ}$ de janeiro de 2019 a EBC acorda sob nova direção e com a sensação de que um projeto de TV efetivamente pública seria definitivamente arquivado pelo novo mandatário da República. Se em 2007 a criação da EBC e o propósito que a instituiu simbolizaram um marco histórico para o serviço público de comunicação no país, em 2019 o horizonte se apresentava na contramão de todos os princípios constitutivos da empresa.

Em estudo do orçamento da EBC, Pieranti desconstruiria o argumento bolsonarista de ônus expressivo da empresa para o governo federal com os dados da redução gradual nos últimos anos dos recursos destinados à empresa, agora limitados ao pagamento de funcionários e das despesas operacionais básicas: “A EBC não é 'cara demais' - muito pelo contrário. Seus custos, quando ponderados em função da população do país, são inferiores aos de entidades congêneres de diversos outros países” (2020, p. 19).

No mesmo trabalho, o pesquisador rebateria a outra justificativa arrolada por Bolsonaro para privatizar ou extinguir a empresa: o baixo índice de audiência. Esse ponto estaria relacionado a investimentos, no caso específico da TV: "Considerando a amostra de países europeus mencionados, um alto orçamento per capita parece guardar relação com melhores resultados em termos de audiência, pelo menos entre as emissoras de TV" (2020, p. 19). Para Pieranti, as críticas à EBC teriam como pano de fundo um único propósito: "uma tentativa de desacreditar o projeto de radiodifusão pública no país" (2020, p. 9).

Ainda que a ideia de um modelo de sistema público de radiodifusão se mostrasse distante do ideal ou mesmo das experiências bem-sucedidas em outros países, o fato é que não se tratava mais de uma questão conceitual para se obter excelência no serviço, mas em última análise tudo o que se conquistou e que foi historiado sobre a radiodifusão

3 "Bolsonaro diz que vai extinguir ou privatizar a TV Brasil, criada por Lula", UOL, 29 out. 2018 (disponível em: https://noticiasdatv.uol.com.br/noticia/televisao/jair-bolsonaro-diz-que-vai-extinguir-ouprivatizar-a-tv-brasil-criada-por-lula-23012?cpid=txt), e "Promessa de campanha, EBC será extinta, afirma Bolsonaro", O Globo, 31 maio 2019 (disponível em: https://oglobo.globo.com/brasil/promessa-decampanha-ebc-sera-extinta-afirma-bolsonaro-23708282). 
pública no Brasil estaria na iminência de se desfazer, se desviar ou de se submeter ao apetite voraz do mercado, organismos religiosos ou das incursões de interesse político.

Em face dos vestígios deixados, os indicadores que subsidiam a eficácia de um sistema público de comunicação no Brasil não prosperam num ambiente inóspito. Sob a nova direção, a tragédia não só se confirma, como se agrava com o desmonte da estrutura, com a descaracterização da finalidade da empresa e com a intenção de privatizá-la ou extingui-la.

Portanto, o direito à comunicação, à informação de interesse, utilidade e de alcance à população (aportes constitutivos de um sistema público de comunicação produtivo) são prerrogativas singulares de uma atmosfera verdadeiramente democrática. Porque num sistema em que a sociedade civil segue à margem da fiscalização e da participação nas tomadas de decisões sobre políticas públicas de comunicação para um sistema público de comunicação à feição da EBC, não se propõe transparência, nem cidadania, mas a supressão gradativa e categórica da democracia.

\section{Considerações finais: da concepção do ideal à percepção do real}

Para Bucci (2008b), a ética da informação e as leis que regem o jornalismo são indivisíveis da ética republicana, preceitos que devem visivelmente subsidiar cada instituição do ambiente democrático brasileiro, e tem na cidadania a centralidade do exercício de aprimoramento do conteúdo midiático.

O projeto de democratizar a comunicação do Estado brasileiro, inserido num viés apartidário e impessoal, no intuito de atender à sociedade e o direito à informação, passa pelo enfrentamento de obstáculos quase que intransponíveis, decorrentes de uma cultura enraizada no Estado, nos partidos, nas empresas públicas e em boa parte da sociedade. O problema está na cultura, nos costumes e na convenção estabelecida há tempos no imaginário político brasileiro (BUCCI, 2008a).

No que concerne à EBC, é visível a ausência de um espírito democrático, pois o governo da vez investe no desmanche da concepção da ideia de sistema público de comunicação. Idealizada em fórum nacional respaldado por entidades representativas da área da comunicação e da sociedade civil e mesmo em uma década de existência ter sido agraciada com 150 prêmios nacionais e internacionais derivados da qualidade dos 
conteúdos jornalísticos e culturais, a empresa passa a depender do complexo social ativo para a sobrevivência de um sistema público comunicacional na inóspita - por deflagrar reações adversas do establishment midiático privado - seara das políticas de comunicação no Brasil e no igualmente instável campo nacional da economia política da informação, da comunicação e da cultura.

\section{Referências}

ARATO. A.; COHEN, J. 1994. Sociedade civil e teoria social. In: AVRITZER. L. (coord.). Sociedade civil e democratização. Belo Horizonte: Del Rey, 1994. p. 147-182.

BOBBIO, N. Ensaios sobre Gramsci e o conceito de sociedade civil. 2. ed. São Paulo: Paz e Terra, 2002.

BOBBIO, N. O conceito de sociedade civil. Rio de Janeiro: Edições Graal, 1982.

BRASIL. Constituição da República Federativa do Brasil. 9. ed. São Paulo: Saraiva, 1994.

BRASIL. Empresa Brasil de Comunicação. Institucional. Sobre a EBC. Brasília, 2016. Disponível em: https://www.ebc.com.br/institucional/sobre-a-ebc/o-que-e-aebc/2012/09/historico. Acesso em: 19 nov. 2020.

. Empresa Brasil de Comunicação. EBC é a instituição federal mais elogiada do Brasil em 2019. Disponível em: https:/www.ebc.com.br/institucional/sala-deimprensa/noticias/2020/01/ebc-e-a-instituicao-federal-mais-elogiada-do-brasil-em-2019. Acesso em: 19 nov. 2020.

Empresa Brasil de Comunicação. EBC coleciona 150 prêmios em pouco mais de 10 anos de história. Disponível em: https://www.ebc.com.br/institucional/sobre-a-ebc/ebccoleciona-mais-de-120-premios-em-pouco-mais-de-10-anos-de-historia. Acesso em: 19 nov. 2020 .

BRASIL. Lei $\mathbf{n}^{\mathbf{0}}$ 11.652, de 7 de abril de 2008. Brasília, DF, 2008. Disponível em: http://www.planalto.gov.br/ccivil_03/_ato2007-2010/2008/lei/111652.htm. Acesso em: 19 nov. 2020 .

BUCCI, E. A razão de ser das emissoras públicas na democracia. UOL. abr./jun. 2008a. Disponível em: <http://twixar.me/vVRT>. Acesso em: 12 nov. 2020. 
Em Brasília, 19 horas: a guerra entre a chapa-branca e o direito à informação no primeiro governo Lula. Rio de Janeiro: Record, 2008b.

CHOMSKY, N. Mídia: propaganda política e comunicação. São Paulo: Martins Fontes, 2014. Disponível em: < http://twixar.me/4rRT>. Acesso em: 13 nov. 2020.

COUTINHO, C. N. Gramsci: Um estudo sobre seu pensamento político. Rio de Janeiro: Campus, 1992.

COUTINHO, C. N. Cultura e sociedade no Brasil: ensaios sobre ideias e formas. 4. ed. São Paulo: Expressão Popular, 2011.

DAHL, R. A. A democracia e seus críticos. São Paulo: Martins Fontes, 2012. Disponível em: $<$ http://twixar.me/67jT $>$. Acesso em: 13 nov. 2020.

GIDDENS, A. A terceira via: Reflexões sobre o impasse político atual e o futuro da socialdemocracia. Rio de Janeiro: Record, 1999.

HABERMAS, J. Direito e democracia: entre facticidade e validade. Volume II. Rio de Janeiro: Tempo Brasileiro, 1997.

KUHN, T. S. A Estrutura das Revoluções Científicas. 5. ed. São Paulo: Perspectiva, 1998.

LARANGEIRA, Á. N. Prefácio. In: CARDOSO, M.; IACOMINI JR., F.; PRADO JR., T. (orgs.). Comunicação e Política: EBC e o impeachment do governo Dilma. Beau Bassin-Mauritius: Novas Edições Acadêmicas, 2018, p. 3-5.

LEAL FILHO, L. L. Prefácio. In: INTERVOZES. Sistemas públicos de comunicação no mundo: experiência de doze países e o caso brasileiro. São Paulo: Paulus, 2009, p. 13-16. (Coleção Comunicação).

PIERANTI, O. P. A radiodifusão pública é “cara demais"? Uma avaliação do orçamento da EBC. Revista Eptic, vol. 22, n. 3, set.-dez., 2020. Disponível em: https://seer.ufs.br/index.php/eptic/article/view/12736. Acesso em: 05 nov. 2020.

PIERANTI, O. P. A radiodifusão pública resiste: a busca por independência no Brasil e no Leste Europeu. Brasília: $\quad$ FAC-UnB, 2018. Disponível em: https://livros.unb.br/index.php/portal/catalog/view/25/19/98-1. Acesso em: 05 nov. 2020.

PIERANTI, O. P. O Estado e as Comunicações no Brasil. FGV Ebape, v. 4, n. 3, 2006. Disponível em: < http://twixar.me/GjJT>. Acesso em: 05 nov. 2020. 
RAMOS, M. C. A Contribuição para o Fomento da Radiodifusão Pública e o paradoxo de financiar o NBR. Teletime, São Paulo, 14 abr. 2019. Disponível em: https://teletime.com.br/17/04/2019/a-contribuicao-para-o-fomento-da-radiodifusao-publica-e-oparadoxo-de-financiar-o-nbr/. Acesso em: 05 nov. 2020.

RAMOS, M. C. Sobre a importância de repensar e renovar a ideia de sociedade civil. In: RAMOS, M. C.; SANTOS, S. dos (orgs.). Políticas de Comunicação: buscas teóricas e práticas. São Paulo: Paulus, 2007, p. 13-48. (Coleção Comunicação).

SANTOS, S. dos; SILVEIRA, É. da. Serviço público e interesse público nas comunicações. In: RAMOS, M. C.; SANTOS, S. dos. Políticas de Comunicação: buscas teóricas e práticas. São Paulo: Paulus, 2007, p. 49-82. (Coleção Comunicação).

VALENTE, J. Concepções e abordagens conceituais sobre sistema público de comunicação. In: INTERVOZES. Sistemas públicos de comunicação no mundo: experiência de doze países e o caso brasileiro. São Paulo: Paulus, 2009a, p. 25-46. (Coleção Comunicação).

. Sistema público de comunicação da Alemanha. In: INTERVOZES. Sistemas públicos de comunicação no mundo: experiência de doze países e o caso brasileiro. São Paulo: Paulus, 2009b, p. 47-62. (Coleção Comunicação).

Sistema público de comunicação da França. In: INTERVOZES. Sistemas públicos de comunicação no mundo: experiência de doze países e o caso brasileiro. São Paulo: Paulus, 2009c, p. 157-174. (Coleção Comunicação).

Sistema público de comunicação do Reino Unido. In: INTERVOZES. Sistemas públicos de comunicação no mundo: experiência de doze países e o caso brasileiro. São Paulo: Paulus, 2009d, p. 235-254. (Coleção Comunicação).

Sistema público de comunicação do Brasil. In: INTERVOZES. Sistemas públicos de comunicação no mundo: experiência de doze países e o caso brasileiro. São Paulo: Paulus, 2009e, p. 269-290. (Coleção Comunicação). 